\title{
Living with obstetric fistula
}

During the birth of her first child in 2000 , Fatima Aliyu developed two fistulas: vesicovaginal fistula and a rectovaginal fistula. She is not yet fully cured and anticipates further surgery.

\author{
Fatima Aliyu patient ${ }^{1}$, G Esegbona obstetric gynaecologist specialist ${ }^{2}$
}

${ }^{1}$ Kano, Nigeria ; ${ }^{2}$ Laure Fistula Centre, Murtala Muhammad, Specialist Hospital, Kano, Nigeria

This is one of a series of occasional articles by patients about their experiences that offer lessons to doctors. The BMJ welcomes contributions to the series. Please contact Peter Lapsley (plapsley@bmj.com) for guidance.

When we arrived at the clinic I was just at the beginning of labour. I stayed there for a day and the pain kept increasing. One of the nurses asked me to push so as to increase the labour. I continued pushing with no sign of delivery. The next day a doctor came and told me that the labour was not progressing. He said I should be induced so that I could deliver.

There was no sign of delivery except the kicking of the baby in my womb. During my third day at the hospital the nurse on duty heard me screaming because of the terrible pain. She said "You are the only one giving us a problem and it is because you are so lazy. It is as if you are not a woman. Can't you see all the other mothers have delivered and gone home with their babies?" She told me to stand up and start going up and down. The nurse said that moving this way might help me to deliver. I started doing as she said and then something burst out of me. Black water started trickling down my legs. She said "Maybe now you are going to deliver." For over 30 minutes I was pushing on the bed but nothing progressed. On the fourth day when I felt like urinating nothing came out, only blood. By now I couldn't walk, my legs were very heavy as if they were frozen.

On the sixth day I started losing consciousness and my mother was terrified that I might not survive. My parents asked the management staff to refer me to a better hospital where I could have a caesarean section. By then we knew the baby was already dead because the heartbeat could not be felt. I went by bus to the next hospital. We were lucky to find a doctor there who was very sympathetic. She asked my relatives how they could leave me in this condition.

I was not aware that I had developed a fistula until after the caesarean. I was brought to the postoperative care unit with a catheter. After seven days, the catheter was removed and I found myself lying in a stream of water. I was shocked when I realised that I could not control my bladder as I had before. My mother saw me and asked why I had poured water on my bed. I told her it was not water and that it felt like urine was coming out uncontrolled. One of the nurses said it was vesicovaginal fistula. My mother screamed and I started crying. I knew it was something terrible because one of our neighbours has vesicovaginal fistula. My neighbour's husband rejected her and her relations left her; her baby was stillborn, and she never had another child because no other men would marry her. She became destitute and had to beg on the street, right into old age.

The diagnosis affected me seriously and I started thinking about the future. My hope was that I should recover and catch up with my colleagues who had started registering for their second year at university. I wondered how I could go back to university in this condition? How could I mix with my classmates with urine trickling down legs that don't work? I cried in silence in the dark, because I was left behind, my dignity had gone, and I didn't know when my problem could be solved. The healthcare staff referred me to the fistula unit in the Murtala Specialist Hospital at Kano.

\section{At the fistula unit}

The doctor said I had two different and difficult fistula complications, a vesicovaginal fistula and a rectovaginal fistula. I also had paralysed nerves in my legs (drop foot), which meant a lot of damage had been done during labour. The surgery needed to be done by an experienced European surgeon who was coming in two weeks' time. The healthcare staff said that the specialist was always willing to do the work, and wanted to help solve our problems. I was happy to hear that the doctor was so dedicated and sympathetic.

After that the days were long and always the same. My mattress was always wet, with urine all over. In cold weather urine would penetrate down the mat and flow under my bed. My mother (I call her Hajiya) would make sure my bed was always dry by using large towels and a macintosh as if making a baby's bed. That would help me to sleep well. Without this, urine would 
disturb me at night and cause rashes and other infections on my skin.

I looked very thin and anaemic. I always passed everything I ate so I limited the amount of food I took.

Hajiya was always telling me to go out and stretch my legs. But I told her I didn't want to, because the pain in my legs became intense and I moved slowly because of my drop foot. In the middle of the night I could not sleep. My eyes were open, turning from one side to the other until morning. If Hajiya forced me to go out I would start crying.

Whenever I did go out I saw girls and women everywhere with wet, urine-soaked clothing who were overcome with sorrow and poverty, this touched my heart and made it beat fast. And every day new women with fistulas came to the medical centre, most of them from poor villages with little education. Some of them had had fistula for ten to 12 years and their ambition in life, their focus, was always to be cured and to be normal. Some had been cured but came again with one, two, three, or more fistulas after bearing more children because there was no one to deliver their babies properly. These women slept and lived under a tree in the fistula compound. They hung their property on the tree trunk, and put their bags under the tree. And in order to eat, to get clothes and a nappy to trap the urine, to survive and to maintain their pride, they went out begging, day and night. It was terrible, and I wondered why women were being injured like this every day.

When the surgeon arrived, he investigated me and told me there was a lot of damage to my body and that, before the repair could be made, I needed to eat more fish and chicken with green vegetables to make myself healthy.

I had several surgeries because the sphincters that controlled my urine and bowels were lost due to trauma so I was incontinent. So far I have had surgery four times and I am still not healed because of the extreme nature of my fistulas. I am still waiting for the next stage, which I hope will be the last, but I am not sure when to go for that surgery, although my surgeon is always willing to assist. I feel good whenever I think of my surgeon. He always cares for my condition; he has always given me treatment whenever the need has arisen. But I am traumatised by having had a fistula at the age of 25 , and by losing my status as a mother, wife, and university graduate for ten years. And it takes courage to face more painful surgery with no guarantee. Now I am searching for whatever might lead me to a better life and a better future. Because fistula is stressful you have to be strong or you could end up losing your whole life.

My family never rejected me. They continue to support me and encourage me to be strong. At first my husband loved and cared for me, but after I developed this problem he stopped everything he had been doing for me, seeing me as being of no use. I have been staying with my parents for the past 10 years. I am now divorced.

I have not given birth again and, in a society in which children are very important to every woman of child-bearing age that is very damaging to my pride. This is the most distressing aspect of my condition. I am always hoping for the day when I will heal and have a way of giving birth to a child again.

What has really made a difference is my level of education. If I was uneducated, like most women with fistula, the stigmatisation would be worse. Before my fistula I didn't even know what a non-governmental organisation was, but I have now learnt a lot about how to be an advocate for people with reproductive health problems and to mobilise them. I have learnt that fistula is a condition that is almost entirely preventable with timely medical intervention. It can be caused by bad service delivery in the medical world and thus negligence. I know that I am in the same position as any other woman with fistula, no matter what my educational background. I therefore have to join hands with the poorest women in the world, to prevent fistula and to help my sisters with fistula to fight for their dignity and rehabilitation. And we must do that, or the trauma of vesicovaginal fistula will continue to affect the lives of thousands of good mothers of childbearing age.

Competing interests: All authors have completed the Unified Competing Interest form at www.icmje.org/coi_disclosure.pdf (available on request from the corresponding author) and declare: no support from any organisation for the submitted work; no financial relationships with any organisations that might have an interest in the submitted work in the previous three years; no other relationships or activities that could appear to have influenced the submitted work.

Provenance and peer review: Not commissioned, not externally peer reviewed.

Accepted: 13 March 2011

Cite this as: $B M J 2011 ; 342: \mathrm{d} 2881$ 


\section{A doctor's perspective}

Annually many millions of women die or are injured and disabled in the process of giving birth. The most prominent among these injuries is obstetric fistula, which until the beginning of this century was common in many women around the world. The condition is caused by lack of prompt medical attention, which leads to prolonged, obstructed labour. The presenting fetal part, unable to pass through the birth canal presses against the soft tissues of the mother's pelvis for days. This impact can cut off the blood supply to large parts of the vagina, bladder, and rectum, resulting in the death of these tissues. If the patient survives labour, during the days and weeks after the birth the dead tissue falls away, leaving holes (fistulas), which allow a constant, uncontrollable loss of urine (vesicovaginal fistula) or stool (rectovaginal fistula) into the vagina. Unless they can get treatment, women with fistula have to live with this incontinence and are likely to face debilitating physical, psychological, social, and economic consequences because of the strong odour that accompanies them. The constant leaking can cause skin ulcerations in the genital area and the smell may drive away her family and community. The trauma is often compounded by the psychological trauma of delivering a stillborn baby.

Today most obstetric fistulas occur in developing countries of sub-Saharan Africa, south Asia, and the Middle East; more than two million women already have the problem and there are 50 000-100 000 new cases every year. Fistulas can be repaired surgically with a success rate of over $90 \%$ in experienced hands. However repairing fistula injuries is not the end of the challenge, because women will return to the same conditions that caused the injury in the first place. Subsequent pregnancies, if they are possible, can undo the success of treatment if women do not receive the care that they need. The capacity for surgical intervention for fistulas is limited; at best, 10000 fistulas can be repaired a year. And too few surgeons have the expert knowledge and skill needed to cope with the large range of traumas present in obstetric fistula. In reality it is not simply a discrete entity of holes that need to be closed, but a widespread, complex trauma to multiple structures in the pelvis, such as the muscles, fascia, and nerves, which can result in a minute fistula with minimal tissue loss. In addition to such major tissue loss, damage can occur to other body systems, such as neurological damage and paralysis in the legs (drop foot) and a complete cloaca - where the rectum, vagina, bladder, and urethra conflux into a single common channel. Closing such a complicated fistula, which is estimated to occur in about $1 \%$ of patients, is a challenge and many women are rendered incurable, or need several attempts to close the fistula.

Because of these factors it is crucial that prevention efforts and new treatment strategies are strengthened and emphasised in tandem with surgical repair. One new way is supported by the National Nigerian fistula programme, which estimates that systematic early catheterisation of small fistulas within 75 days of leaking could cure over $25 \%$ of all new cases each year without the need for fistula surgery.

It is also important to not just simply focus on the development issues inextricably linked with fistula such as poverty, lack of education for girls, and early marriage and pregnancy. If marriage, childbirth or both were delayed by legislation or by promoting access to family planning services, this would only help women delay developing a fistula until later on if they could not obtain timely, high quality obstetric help. Nor is it any use to identify mothers who are at risk during the antenatal stage or to empower and educate women about their right to health care if, while in hospital, they are neglected as much as or more than they would be at home. As Fatima's case shows, timely skilled care during pregnancy and childbirth when women need it is crucial. Failure to address this aggressively will only ensure that the problem of maternal morbidity and mortality endures.

Gloria Esegbona

\section{Further reading}

Useful resources for patients and health professionals

Campaign to end fistula (www.endfistula.org) - This campaign is an international effort that currently covers over 40 countries in sub-Saharan Africa, South Asia, and some Arab States. Launched by the United Nations Population Fund (UNFPA) in 2003, the campaign includes interventions to prevent fistula from occurring, to treat women who are affected, and to help women who have undergone treatment return to full and productive lives, with the ultimate goal of making fistula as rare in the developing world as it is in industrialised countries.

International society of obstetric fistula surgeons (www.isofs.org)-ISOFS is the leading international professional body for those engaged at the forefront of the treatment and rehabilitation of women with obstetric fistula. Its aim is to scale up the number of skilled professionals who can offer a quality repair.

The National Nigerian Fistula Project (http://www.isofs.org/wp-co ntent/uploads/2011/04/report_2010_000_full_report_LR.pdf)_Over the past 25 years this project has become the largest fistula repair and training centre in the world. Founded and led by Dr Kees Waaldjik, an experienced fistula surgeon. The project includes eight fistula repair centres in the north of Nigeria and one in the south, with additional support provided to three centres in Niger. 